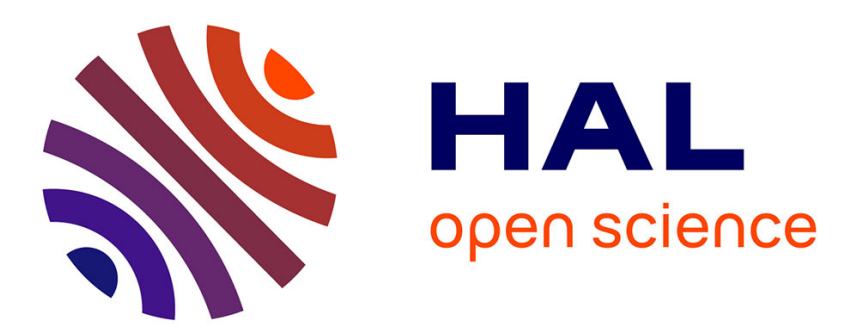

\title{
MnO2-coated Ni nanorods: Enhanced High Rate Behavior in Pseudo-Capacitive Supercapacitor
}

Yannick Lei, Barbara Daffos, Pierre-Louis. Taberna, Patrice Simon, Frédéric

Favier

\section{- To cite this version:}

Yannick Lei, Barbara Daffos, Pierre-Louis. Taberna, Patrice Simon, Frédéric Favier. MnO2-coated Ni nanorods: Enhanced High Rate Behavior in Pseudo-Capacitive Supercapacitor. Electrochimica Acta, 2010, 55 (25), pp.7454. 10.1016/j.electacta.2010.03.012 . hal-00560483

\section{HAL Id: hal-00560483 \\ https://hal.science/hal-00560483}

Submitted on 3 Sep 2013

HAL is a multi-disciplinary open access archive for the deposit and dissemination of scientific research documents, whether they are published or not. The documents may come from teaching and research institutions in France or abroad, or from public or private research centers.
L'archive ouverte pluridisciplinaire HAL, est destinée au dépôt et à la diffusion de documents scientifiques de niveau recherche, publiés ou non, émanant des établissements d'enseignement et de recherche français ou étrangers, des laboratoires publics ou privés. 


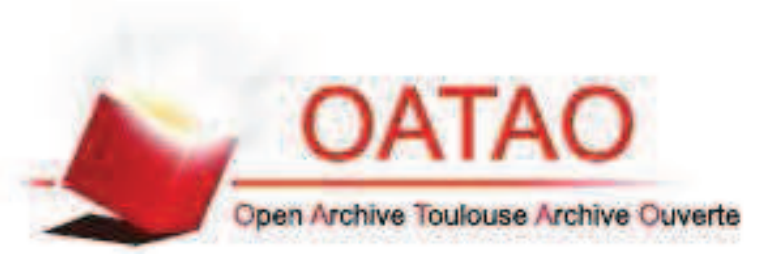

\section{Open Archive Toulouse Archive Ouverte (OATAO)}

OATAO is an open access repository that collects the work of Toulouse researchers and makes it freely available over the web where possible.

This is an author-deposited version published in: http://oatao.univ-toulouse.fr/ Eprints ID: 8673

To link to this article: DOI: $10.1016 /$ j.electacta.2010.03.012

URL: http://dx.doi.org/10.1016/j.electacta.2010.03.012

To cite this version: Lei, Yannick and Daffos, Barbara and Taberna, Pierre-Louis and Simon, Patrice and Favier, Frédéric MnO2-coated Ni nanorods: Enhanced high rate behavior in pseudo-capacitive supercapacitor. (2010) Electrochimica Acta, vol. 55 ( $\left.\mathrm{n}^{\circ} 25\right)$. pp. 74547459. ISSN 0013-4686 


\title{
$\mathrm{MnO}_{2}$-coated Ni nanorods: Enhanced high rate behavior in pseudo-capacitive supercapacitor
}

\author{
Y. Lei ${ }^{\text {a }}$, B. Daffos ${ }^{\text {b }}$, P.L. Taberna ${ }^{\text {b }}$, P. Simon ${ }^{\text {b, }}{ }^{\text {, F. Favier }}{ }^{\mathrm{a}, *, 1}$ \\ a Institut Charles Gerhardt Montpellier - AIME, UMR 5253, Université Montpellier 2, Place Eugène Bataillon, 34095 Montpellier Cedex 5, France \\ b CIRIMAT UMR CNRS 5085, Université Paul Sabatier Toulouse 3, 31062 Toulouse Cedex 4, France
}

Keywords:

A B S T R A C T

Ni nanorods prepared by electrochemical growth through an anodized aluminium oxide membrane were used as substrate for the electrodeposition of $\mathrm{MnO}_{2}$ either in potentiostatic mode or by a pulsed method. Electrochemical deposition parameters were chosen for an homogeneous deposit onto Ni nanorods. Resulting Ni supported $\mathrm{MnO}_{2}$ electrodes were tested for electrochemical performances as nanostructured negative electrodes for supercapacitors. They exhibited initial capacitances up to $190 \mathrm{~F} / \mathrm{g}$ and remarkable

Supercapacitor performances at high charge/discharge rates.

Manganese dioxide

Coating

Nanorods

High rate capacitance

\section{Introduction}

$\mathrm{MnO}_{2}$ was first proven as performing electrode material for supercapacitors by Goodenough and co-workers [1,2]. The elucidation of the charge storage mechanism involving the $\mathrm{Mn}^{4+} / \mathrm{Mn}^{3+}$ redox couple led to the calculation of a maximum theoretical capacitance of $1100 \mathrm{~F} / \mathrm{g}$ for a $1 \mathrm{~V}$ electroactive potential range [3,4]. However, highest reported capacitances for bulk electrodes have never reached such a high value, but merely $300 \mathrm{~F} / \mathrm{g}[5,6]$. Among the main causes pointed out for these limited performances, the limited charge percolation behavior through the material thanks to the poor electrical conductivity of $\mathrm{MnO}_{2}$. Therefore, the use of $\mathrm{MnO}_{2}$ thin films appears an attractive potential route to overcome this limit: electrochemical reactions at the electrolyte and active material interface take place only few nanometers apart from the current collector (CC) where generated charges are collected. Performances are improved in terms of gravimetric capacitance relative to $\mathrm{MnO}_{2}$ content but the total energy stored by the device is however limited by the small quantity of deposited active material at the planar CC surface. The use of nanostructured CC developing larger surface areas makes then obvious sense. This strategy

* Corresponding author at: Institut Charles Gerhardt Montpellier - AIME, UMR 5253, Université Montpellier 2, Place Eugène Bataillon, cc 1502, 34095 Montpellier Cedex 5, France. Tel.: +33 4671433 32; fax: +33 467143304

E-mail address: fredf@univ-montp2.fr (F. Favier).

1 ISE member. has been previously developed and electrochemical performances of $\mathrm{MnO}_{2}$-coated carbon with small mesopores [7] or carbon nanotubes [8] composite electrodes have been reported to capacitances at $220 \mathrm{~F} / \mathrm{g}$ and $141 \mathrm{~F} / \mathrm{g}$ respectively. The limited accessibility of liquid electrolyte to the whole mesoporous volume as well as the limited charge percolation have been pointed out to explain these somehow disappointing performances. Depositing very thin $\mathrm{MnO}_{2}$ films on flat $\mathrm{Ni}$ current collectors has led to impressive capacitance values up to $400 \mathrm{~F} / \mathrm{g}$ [4]. On the other hand, $200 \mathrm{~F} / \mathrm{g}$ capacitances have been obtained from $\mathrm{MnO}_{2}$ deposited onto Ni substrates nanostructured by etching [9].

We have recently reported the preparation of mesoporous carbon/ $\mathrm{MnO}_{2}$ composite electrode material and showed that the capacitance extracted from $\mathrm{MnO}_{2}$ deposited at the surface of large mesopores (up to $150 \mathrm{~nm}$ in diameter) could reach high value up to $900 \mathrm{~F} / \mathrm{g}$ (relative to $\mathrm{MnO}_{2}$ weight content), close to the maximum theoretical one [10]. However, the capacitance of the composite electrode itself did not exceed $180 \mathrm{~F} / \mathrm{g}$ because of the low $\mathrm{MnO}_{2}$ content ( $9 \mathrm{wt} \%$ for the most performing electrode) and the corresponding dead-weight from the mesoporous carbon current collector. It is also anticipated that electrochemical performances could be improved by a more homogeneous dispersion of the active material into the porous volume. In that matter, anodic deposition is an easy and efficient method to perform on monolithic substrates as suggested by recent works from Chang et al. [4]. They prepared a nanostructured $\mathrm{Ni}$ electrode after a selective electrochemical stripping of $\mathrm{Cu}$ contained in their pristine $\mathrm{Cu}-\mathrm{Ni}$ alloy co-deposited on an indium-doped tin oxide substrate (ITO). Their 
prepared $\mathrm{MnO}_{2} / \mathrm{Ni}$ composite electrode exhibited attractive values of capacitance relative to $\mathrm{MnO}_{2}$ content up to $500 \mathrm{~F} / \mathrm{g}$. On the other hand, as CC supporting Li-ion battery anode materials, such nanorod architectures have shown they can remarkably accommodate high charge/discharge rates up to a complete charge or discharge in few minutes using $\mathrm{Fe}_{3} \mathrm{O}_{4}$ [11], $\mathrm{SnO}_{2}$ [12] or other active materials [13,14]. As a critical step for electrochemical performance in supercapacitors, the charge/discharge behavior of $\mathrm{MnO}_{2}$ supported on ordered Ni nanorods remains unexplored.

In this paper, we are presenting an original electrochemical route for the controlled deposition of an $\mathrm{MnO}_{2}$ coating at the surface of well defined Ni nanorods as well as an exploration of the electrochemical behavior of the prepared nanostructured electrodes especially towards charge/discharge rate.

\section{Experimental}

\subsection{Ni nanorods}

Ni nanorods supported onto Ni foil ( $250-\mu \mathrm{m}$ thick, $10 \mathrm{~mm}$ diameter, $99 \% \mathrm{Ni}$, Goodfellow) were prepared following a procedure as described in a previous work [11]. A two-electrode electrochemical cell was used. It included a polished $\mathrm{Ni}$ surface as cathode and a Ni anode separated by a Whatman paper and an AAO membrane. Whatman paper was used as separator and AAO membrane (Whatman, Anodisc 47, reference \#6809 5022) as template for the electrochemical growth of $\mathrm{Ni}$. The plating solution was composed of $\mathrm{NiSO}_{4} \cdot 6 \mathrm{H}_{2} \mathrm{O}(240 \mathrm{~g} / \mathrm{L}), \mathrm{NiCl}_{2} \cdot 6 \mathrm{H}_{2} \mathrm{O}(20 \mathrm{~g} / \mathrm{L})$ and $\mathrm{H}_{3} \mathrm{BO}_{3}(20 \mathrm{~g} / \mathrm{L})$ (Acros Chemicals). Using an Arbin BT2000 potentiostat, a two-step cathodic current pulse method was used for the preparation: (a) $-15 \mathrm{~mA} / \mathrm{cm}^{2}$ for $50 \mathrm{~ms}$ (germination step) then (b) $-1 \mathrm{~mA} / \mathrm{cm}^{2}$ for $250 \mathrm{~ms}$ (growth step).

\section{2. $\mathrm{MnO}_{2}$ coating}

Prior to the anodic deposition of $\mathrm{MnO}_{2}, \mathrm{AAO}$ membrane was dissolved in $\mathrm{NaOH} 1 \mathrm{M}$ (VWR International) etching solution at $80^{\circ} \mathrm{C}$ for $3 \mathrm{~min}$. $\mathrm{MnO}_{2}$ plating solution was composed of $\mathrm{MnSO}_{4} 2 \mathrm{mM}$ and $\mathrm{K}_{2} \mathrm{SO}_{4} 25 \mathrm{mM}$ (99\%, Aldrich) [15]. Ni nanorods were soaked with this solution by a vacuum-assisted impregnation method. $\mathrm{MnO}_{2}$ coating was first performed by a single-step potentiostatic method, at $E_{\text {work }}$ potentials at $0.85 \mathrm{~V}$ and $1.0 \mathrm{~V}$ versus $\mathrm{Ag}-\mathrm{AgCl}$ for 900 s, 1800 s and 3600 s. For comparison purpose, the same electrochemical parameters were used for the single-step potentiostatic deposition of a layer of $\mathrm{MnO}_{2}$ onto a flat Ni foil (Goodfellow). Ni foil was degreased using acetone before use. Alternatively a two-step potentiostatic pulse method was also used: first step at $0.85 \mathrm{~V}$ for $10 \mathrm{~s}$ then second step at open circuit voltage (OCV) for $2 \mathrm{~s}$. In that case, the deposition duration corresponded to the time at $0.85 \mathrm{~V}$. For example, the two-step method was repeated 360 times in order to achieve a deposition of $3600 \mathrm{~s}$. The weight of deposited $\mathrm{MnO}_{2}$ was determined by integration of the total coulombic charges used for deposition over electrolysis durations. Weights were evaluated at $m_{\mathrm{MnO}_{2}}=0.254 \mathrm{mg}$ and $0.339 \mathrm{mg}$ for the two-step depositions onto $\mathrm{Ni}$ nanorods at $0.85 \mathrm{~V}$ for $3600 \mathrm{~s}$ and $7200 \mathrm{~s}$ respectively. $0.250 \mathrm{mg}$ of $\mathrm{MnO}_{2}$ was deposited by two-step electrolysis at $0.85 \mathrm{~V}$ for $3600 \mathrm{~s}$ onto the flat $\mathrm{Ni}$ foil. The total charge $Q$ was calculated by integration of the measured current with respect to the time of deposition. This led to the weight of deposited material $m_{\mathrm{MnO}_{2}}=Q \times M_{\mathrm{MnO}_{2}} / 2 F$, with $F$ the Faraday constant. This weight is however over-estimated since at working potentials of 0.85 or $1.0 \mathrm{~V} / \mathrm{Ag}-\mathrm{AgCl}$, a part of the charge is used for water oxidation and oxygen evolution.

\subsection{Characterizations}

The resulting electrodes were analyzed by Scanning Electron Microscopy (SEM, JEOL JSM6300F), Cyclic Voltammetry (CV) and Electrochemical Impedance Spectrosocopy (EIS).

The electrochemical cell was a conventional three electrode cell composed of an $\mathrm{Ag}-\mathrm{AgCl}$ as reference electrode, a Pt foil as counter-electrode and the composite electrode as working electrode. Electrochemical characterizations were performed in a $\mathrm{K}_{2} \mathrm{SO}_{4} 0.5 \mathrm{M}$ electrolytic solution at room temperature using a Biologic VMP3 potentiostat running under EC-Lab software.

\section{Results}

\subsection{Raw Ni nanorods}

The SEM picture showed in Fig. 1a depicts a quite perfect and dense array of Ni nanorods after dissolution of the AAO membrane. They are about $200 \mathrm{~nm}$ in diameter and $5 \mu \mathrm{m}$ long. As electrochemically grown onto the Ni electrode, they are strongly mechanically and electrically bonded to the metal substrate building a self-supported nanostructured electrode suitable for further active material electrodepositions and tests. As shown in Fig. 2a from a CV in $\mathrm{K}_{2} \mathrm{SO}_{4} 0.5 \mathrm{M}$ at $s=10 \mathrm{mV} / \mathrm{s}$, this electrode made of raw Ni nanorods exhibits a very limited capacitive behavior ( $3.5 \mathrm{mF} / \mathrm{cm}^{2}$ relative to the footprint area of the Ni substrate) in a narrow electrochemical window (from -0.3 to $0.3 \mathrm{~V} / \mathrm{Ag}-\mathrm{AgCl}$ ). Fig. $2 \mathrm{~b}$ shows a CV of the same electrode in the same potential window as usually used for the electrochemical investigations on $\mathrm{MnO}_{2}$-based electrode material (from $-0.05 \mathrm{~V}$ to $0.85 \mathrm{~V} / \mathrm{Ag}-\mathrm{AgCl}$ ). Actually, it mostly shows the oxygen evolution reaction occurring at $\mathrm{Ni}$ surface at potentials higher than $0.6 \mathrm{~V} / \mathrm{Ag}-\mathrm{AgCl} . \mathrm{MnO}_{2}$ deposition potential was extracted from CVs performed in $\mathrm{MnSO}_{4}$ $2 \mathrm{mM}$ and $\mathrm{K}_{2} \mathrm{SO}_{4} 25 \mathrm{mM}$ plating solution (Fig. 3). An oxidation peak $\left(E_{\mathrm{Ox}}\right)$ corresponding to the oxidation on $\mathrm{Mn}^{2+}$ to $\mathrm{Mn}^{4+}$ and $\mathrm{MnO}_{2}$ surface deposition was observed at about $1.0 \mathrm{~V}$. A potential window from $0.85 \mathrm{~V}$ to $1.0 \mathrm{~V}$ was found as suitable for $\mathrm{MnO}_{2}$ deposition.
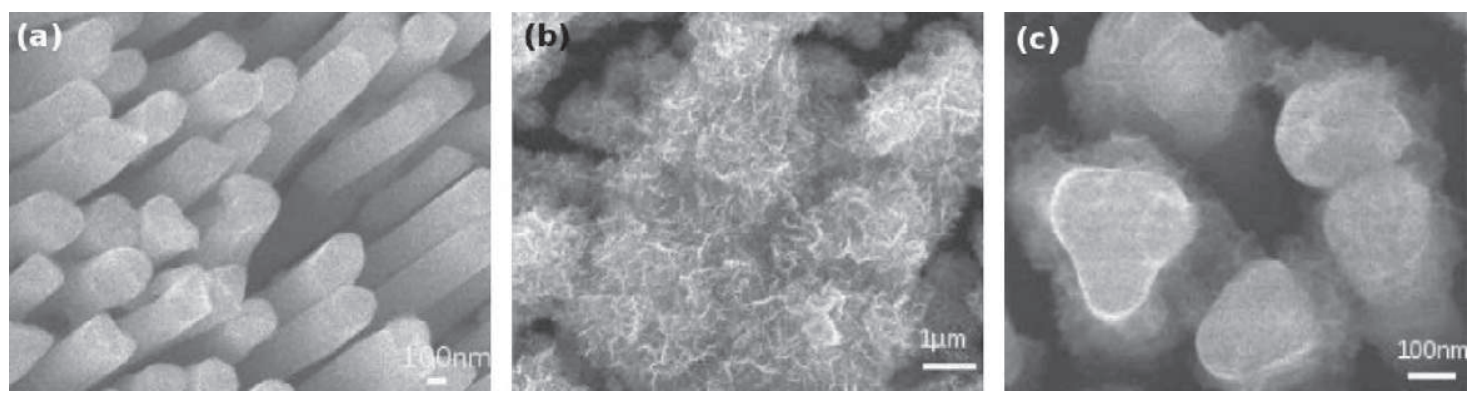

Fig. 1. SEM micrograph of raw Ni nanorods (a) used as substrate for the electrodeposition of $\mathrm{MnO}_{2}$ and $\mathrm{MnO}_{2}$ electrodeposited at $1.0 \mathrm{~V} / \mathrm{Ag}-\mathrm{AgCl}$ for $3600 \mathrm{~s}$ (b) and at $0.85 \mathrm{~V} / \mathrm{Ag}-\mathrm{AgCl}$ for $1800 \mathrm{~s}$ (c) on Ni nanorods. 

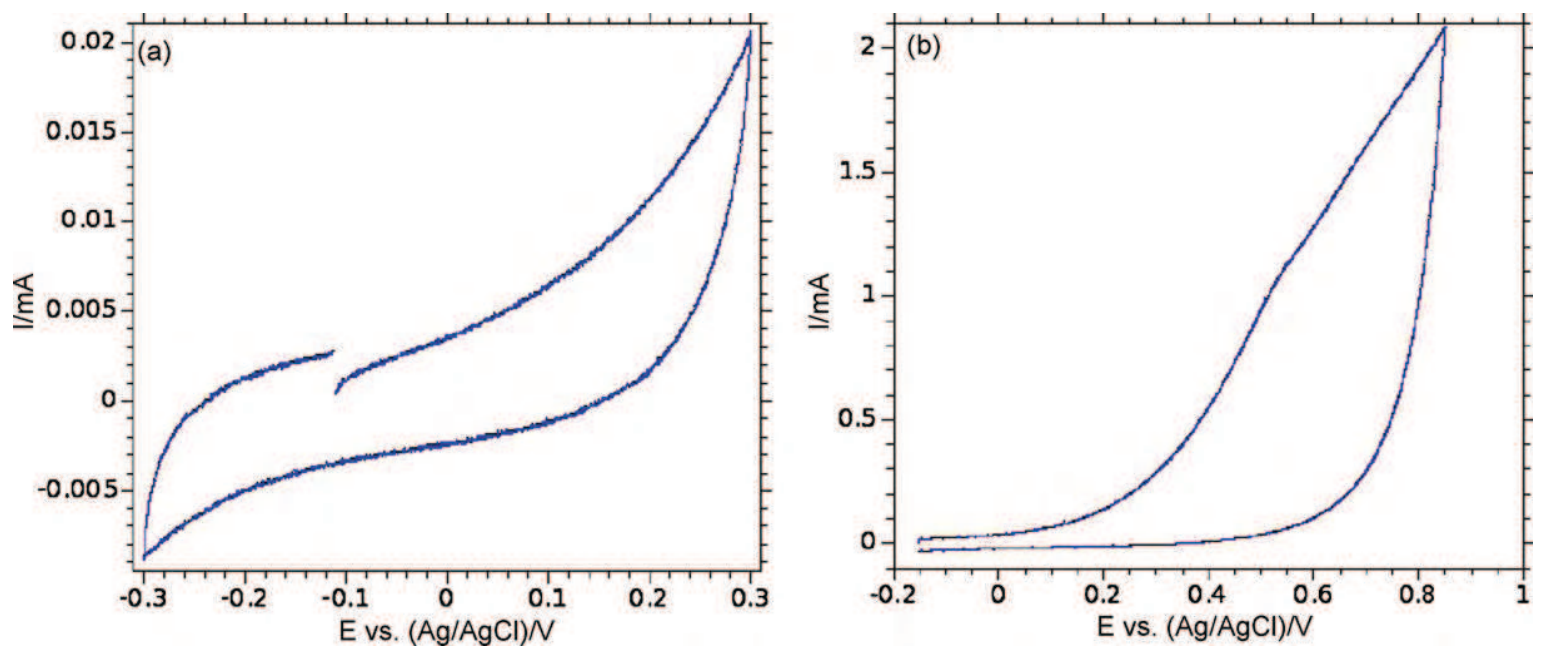

Fig. 2. $\mathrm{CV}$ measured of raw $\mathrm{Ni}$ nanorods in $\mathrm{K}_{2} \mathrm{SO}_{4} 0.5 \mathrm{M}$ to evaluate its capacitance (a) and its stability in a larger potential range (b).

\section{2. $\mathrm{MnO}_{2}$ coating, single-step potentiostatic method}

$\mathrm{Ni}$ nanorods were first used for $\mathrm{MnO}_{2}$ electrodeposition at constant potentials, respectively $1 \mathrm{~V}$ and $0.85 \mathrm{~V} / \mathrm{Ag}-\mathrm{AgCl}$. SEM picture in Fig. $1 \mathrm{~b}$ shows that, at $1.0 \mathrm{~V} / \mathrm{Ag}-\mathrm{AgCl}$ potential, most of $\mathrm{MnO}_{2}$ was deposited at the top of the nanorods. The same deposit morphology was obtained whatever the electrolysis duration. In contrast, at $E_{\text {work }}$ sets to $0.85 \mathrm{~V} / \mathrm{Ag}-\mathrm{AgCl}$, Ni nanoplot surface could be more homogeneously coated by $\mathrm{MnO}_{2}$ (Fig. 1c) for both $1800 \mathrm{~s}$ and $3600 \mathrm{~s}$ electrolysis durations. At both working potentials, $\mathrm{MnO}_{2}$ deposits are composed of dense layers or aggregates of highly disordered nanosheets. The evaluation of electrochemical performances by CV measurements (Fig. 4) exhibits capacitances about $C_{1}=130 \mathrm{~F} / \mathrm{g}$ at first charge/discharge cycle. This initial capacitance value from $\mathrm{MnO}_{2}$ deposit obtained at $0.85 \mathrm{~V} / \mathrm{Ag}$ - $\mathrm{AgCl}$ strongly decreases during the first 100 cycles before to stabilize at $80 \mathrm{~F} / \mathrm{g}$ after 500 cycles. In contrast, the low capacitance value at $80 \mathrm{~F} / \mathrm{g}$ obtained at first cycles for $\mathrm{MnO}_{2}$ deposit prepared at $1.0 \mathrm{~V} / \mathrm{Ag}-\mathrm{AgCl}$, slowly increases upon cycling up to $100 \mathrm{~F} / \mathrm{g}$ after 500 cycles (Fig. 4b).

\section{3. $\mathrm{MnO}_{2}$ coating, two-step potentiostatic method}

To improve the deposit morphology onto the nanorods, an alternative two-step potentiostatic method has been used. It included a rest period at open circuit after a short potentiostatic pulse for

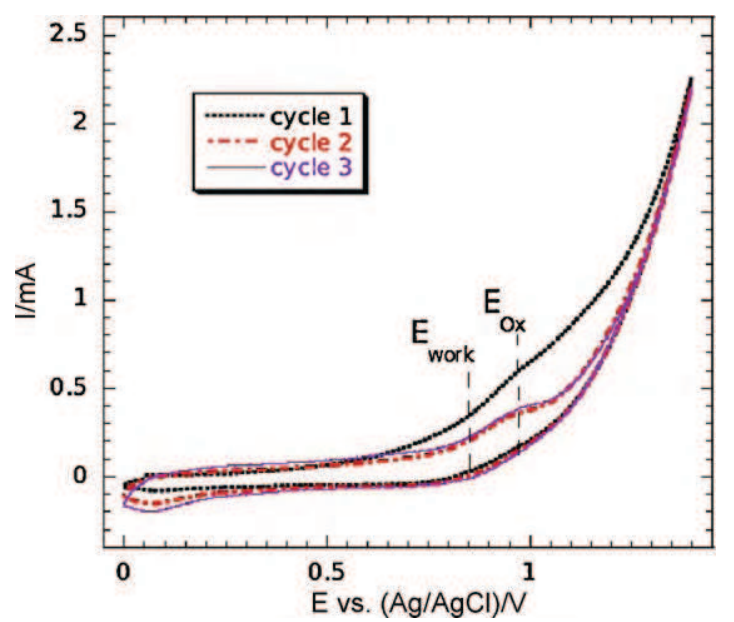

Fig. 3. CVs performed in the platting solution using a Ni nanorods substrate. material growth. This rest step aims to limit the $\mathrm{Mn}^{2+}$ ions depletion close to the Ni surface, avoiding thus a diffusion-controlled deposition reaction. $\mathrm{MnO}_{2}$ depositions were carried out for $3600 \mathrm{~s}$ ( 360 cycles of the two-step method) and 7200 s (720 cycles). SEM pictures in Fig. 5 show the electrode surface after $3600 \mathrm{~s}$ (a) and $7200 \mathrm{~s}$ (b) deposition times. Micrographs show that the voids in between the nanorods are filled more homogeneously using these electrodeposition experimental parameters. The whole surface of the nanorods, top and sides, is covered by an $\mathrm{MnO}_{2}$ layer whose thickness obviously depends on the electrolysis duration or number of electrolysis cycles. However, some voids are still present between the rods to allow electrolyte impregnation. The layered nanostructure is clearly evidenced by electronic contrast showing the bright $\mathrm{Ni}$ core of the nanorods and the gray $\mathrm{MnO}_{2}$ deposit.

The capacitance of the 3600 s-electrode was evaluated by CV ran at various scan rates. The evolution depicted in Fig. 6a shows that capacitances are hardly affected by the scan rates even at high scan rates while remaining close to $100 \mathrm{~F} / \mathrm{g}$. The electrochemical capacitance of the $7200 \mathrm{~s}$-electrode was measured at $C_{1}=190 \mathrm{~F} / \mathrm{g}$ for the first cycle. This quite high value progressively fade down upon cycling and, after 500 cycles, a $20 \%$ loss was observed with $C_{500}=150 \mathrm{~F} / \mathrm{g}$.

\subsection{Electrochemical impedance spectroscopy (EIS)}

EIS analyses were performed at open circuit voltage (OCV) in $\mathrm{K}_{2} \mathrm{SO}_{4}, 0.5 \mathrm{M}$ after 1-5-10-50-100-500 cycles of charge/discharge at $10 \mathrm{mV} / \mathrm{s}$ scan rate. The $\mathrm{MnO}_{2} / \mathrm{Ni}$ nanorods composite electrodes were stabilized at OCV for 1 hour prior to the experiments performed with $U= \pm 10 \mathrm{mV}$ around OCV in the $10^{-2}$ to $50.10^{3} \mathrm{~Hz}$ frequency range. The corresponding Nyquist plots depicted in Fig. 7 were fitted by the Zfit routine from EC-Lab software, used to monitor the experiments.

For the electrode prepared by the single pulse method, EIS analyses did not show any loop at high frequencies characteristic to parallel RC circuit for composite highly porous electrode. Neither could be observed any Warburg-like element, characteristic to semi-infinite diffusion or migration in the porous structure of the electrode [16]. Nyquist plots are characteristic of the non-ideal capacitance behavior of the thick $\mathrm{MnO}_{2}$ layer deposited onto $\mathrm{Ni}$ nanorods since the increase of the imaginary part of the impedance at low frequency deviated from the theoretical vertical line. This non-ideality may originate from slow $\mathrm{MnO}_{2}$ dissolution as solvated $\mathrm{Mn}^{3+}$ or redox leaking currents from impurities present in the electrolyte like dissolved oxygen. For the electrodes prepared by 

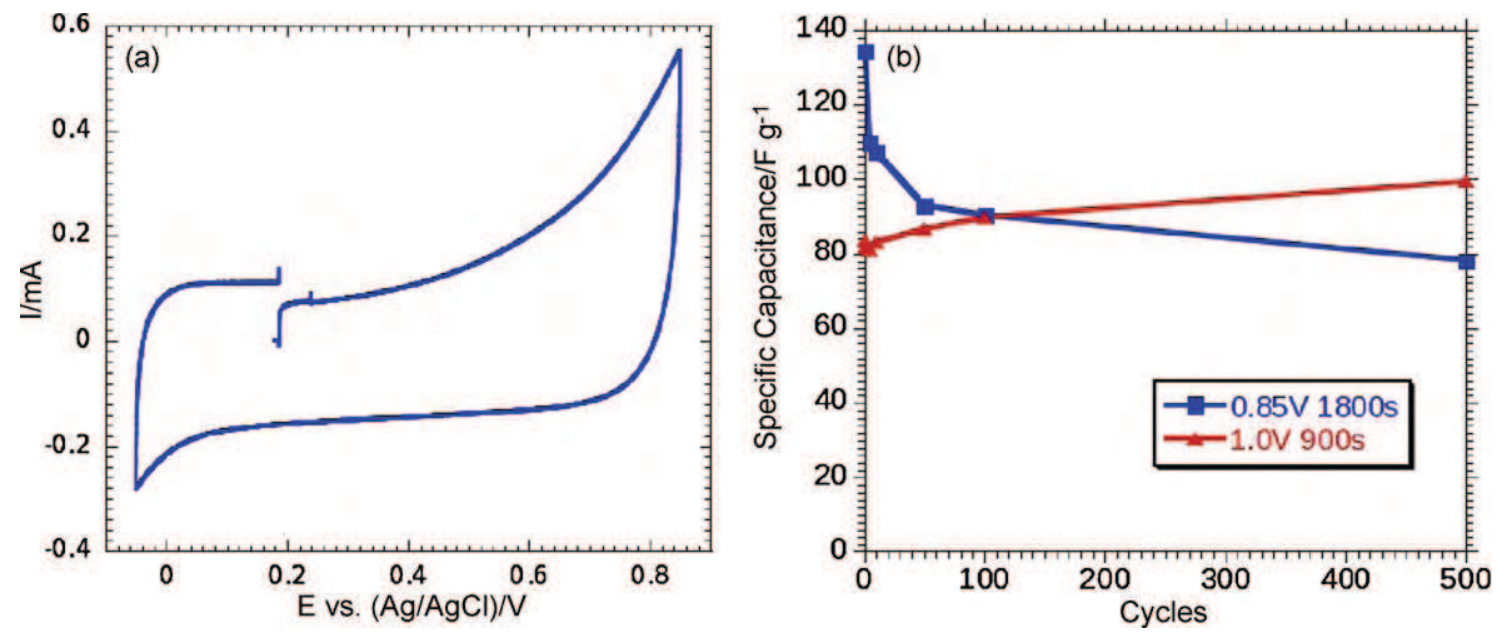

Fig. 4. $\mathrm{CV}$ of $\mathrm{MnO}_{2}$-coated Ni nanorods (single-step method, $1 \mathrm{~V}$ for $900 \mathrm{~s}$ ) in $\mathrm{K}_{2} \mathrm{SO}_{4} 0.1 \mathrm{M}$ (a). Evolution of capacitance upon cycling of an $\mathrm{MnO}{ }_{2}$-coated Ni nanorods electrode (b). Deposition performed by single-step potentiostatic method at $1.0 \mathrm{~V}$ for $900 \mathrm{~s}$ (triangles, $m_{\mathrm{MnO}_{2}}=0.0177 \mathrm{mg}$ ) and at $0.85 \mathrm{~V}$ for $1800 \mathrm{~s}$ (squares, $m_{\mathrm{MnO}}=0.0545 \mathrm{mg}$ ).
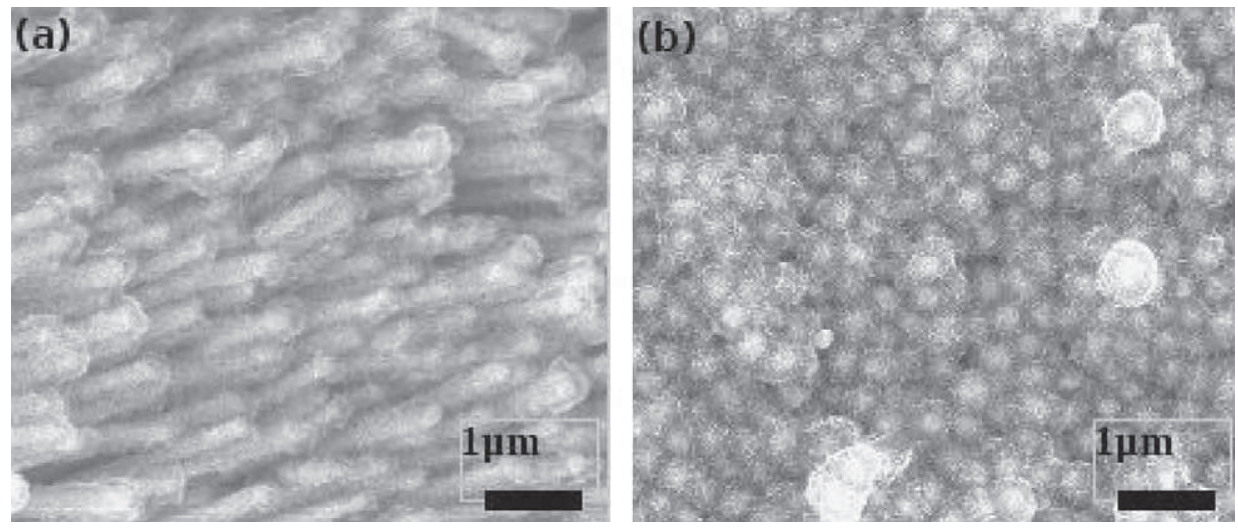

Fig. 5. $\mathrm{MnO}_{2}$ deposited by two-step potentiostatic pulse method at $0.85 \mathrm{~V}$ for $3600 \mathrm{~s}$ (a) and $7200 \mathrm{~s}$ (b) on Ni nanorods.

the two-step pulsed method, Nyquist plots exhibit a semi-infinite diffusion (Warburg element) as well as a non-ideal capacitance behavior. A small loop might also be observed at high frequencies. Above 50 cycles, the general shape of the plots changes and the low frequency capacitive behavior shifts along the $X$-axis to higher resistance.

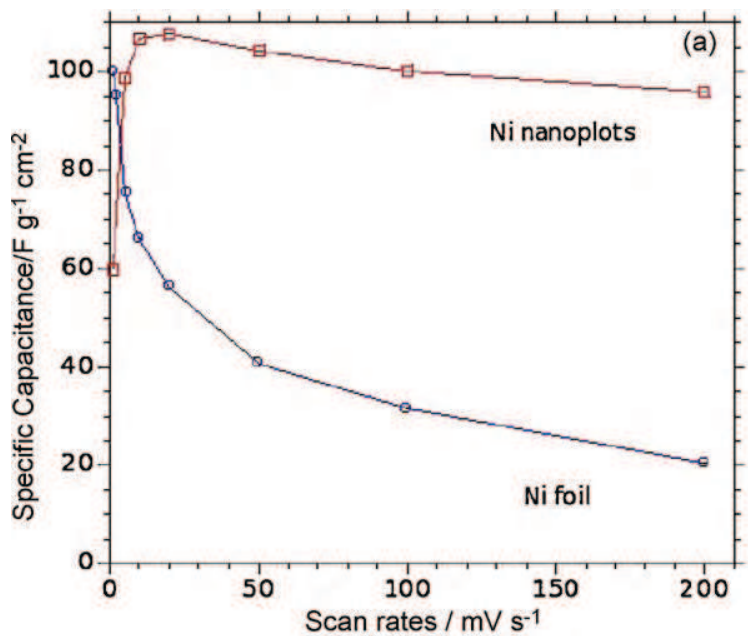

\section{Discussion}

\subsection{Single-step potentiostatic method}

Use of a high anodic working potential (anodic over-potential) leads to an uncontrolled growth of $\mathrm{MnO}_{2}$ onto Ni nanorods. At $1.0 \mathrm{~V}$,

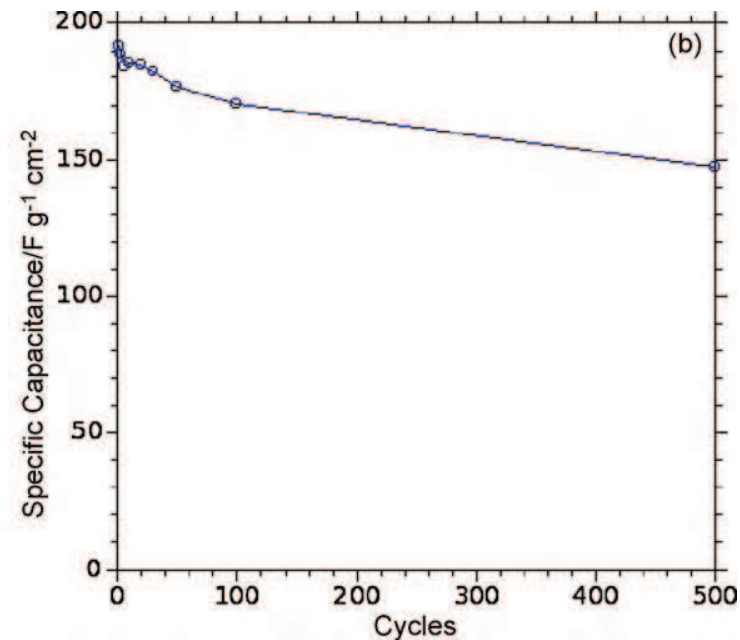

Fig. 6. Evolution of capacitance versus scan rates (a) for $\mathrm{MnO}_{2}$-coated $\mathrm{Ni}$ nanorods (squares, two-step potentiostatic pulse method, $0.85 \mathrm{~V}$ for $3600 \mathrm{~s}$ ) and $\mathrm{MnO} \mathrm{O}_{2}$-coated $\mathrm{Ni}$ flat substrate $(\bigcirc$, two-step potentiostatic pulse method, $0.85 \mathrm{~V}$ for $3600 \mathrm{~s})$. Capacitances are relative to the weight of deposited $\mathrm{MnO}_{2}$ and geometric surface of the electrode. Evolution of capacitance upon cycling (b) of an $\mathrm{MnO}_{2}$-coated Ni nanorods electrode (two-step potentiostatic pulse method, $0.85 \mathrm{~V}$ for $7200 \mathrm{~s}$ ). 

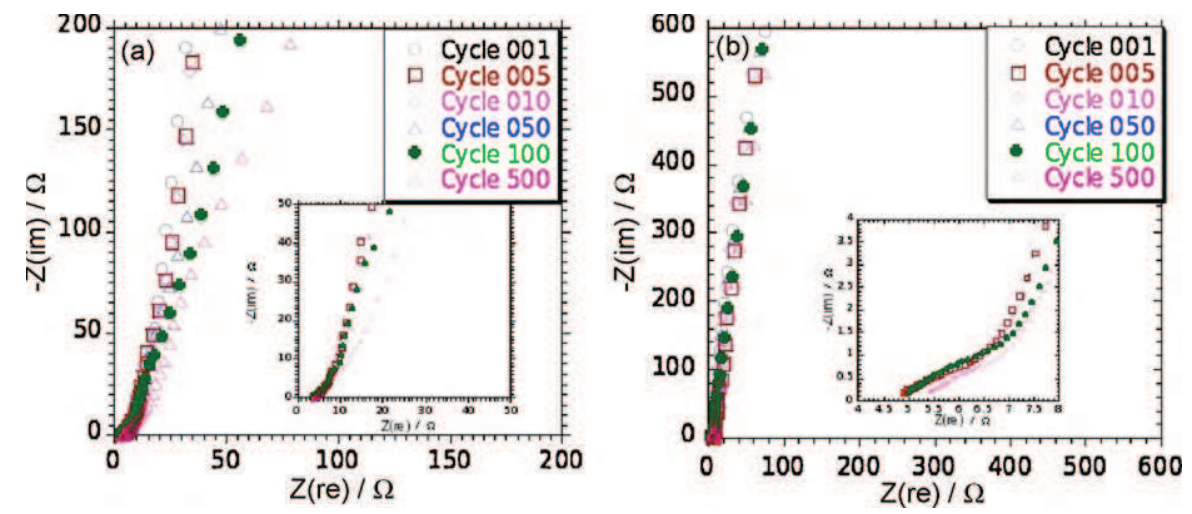

Fig. 7. EIS analyses upon cycling were performed on Ni nanorods coated by $\mathrm{MnO}_{2}$ by single-step method (at $0.85 \mathrm{~V}$ for $900 \mathrm{~s}$ (a) and by two-step potentiostatic pulse method for $7200 \mathrm{~s}(\mathrm{~b}))$.

the growth kinetics are so high as compared to the diffusion of $\mathrm{Mn}^{2+}$ through the nanoplot network that quickly, species suitable for oxidation are made available only at the top surface of the electrode, which is easily accessible for mass transfer. At such a high potential, the growth mechanism is similar to that on a flat electrode: deposit is quite thick and covers only the top of the nanorods (Fig. 1b). Another effect can account for this behavior since the high current density induced by tip effect favors $\mathrm{MnO}_{2}$ deposition preferentially on the nanoplot tops. Decreasing the potential applied to $0.85 \mathrm{~V}$ obviously allows a better control for a more uniform growth of $\mathrm{MnO}_{2}$ in between the nanorods as well as on their tops (Fig. 1c). The decrease of the anodic over-potential allows a more kinetically controlled oxidation process more compatible with the diffusion of $\mathrm{Mn}^{2+}$ species to the electrolyte/electrode interface. At such a potential, the corresponding current density is however rather limited as is the quantity of deposited $\mathrm{MnO}_{2}$.

A comparison of the capacitances measured from the CVs for raw nickel nanorods (Fig. 2b) and those for the same nanostructured substrate covered with a $\mathrm{MnO}_{2}$ layer (Fig. 4a) demonstrates that, the electrochemical contribution of $\mathrm{Ni}$ substrate to the overall electrode capacitance is fairly limited (less than 5\%) whatever the electrolysis parameters selected for the deposition of $\mathrm{MnO}_{2}$. This limited contribution originates from the oxidation of Ni metal to form an $\mathrm{Ni}(\mathrm{OH})_{2}$ protective passivation layer [18]. It also depends on the coverage of the nickel substrate by $\mathrm{MnO}_{2}$ layer. As shown in Fig. $2 \mathrm{~b}$, Ni passivation occurs mild $\mathrm{pH}$ range at potential greater than $0.3 \mathrm{~V} / \mathrm{Ag} / \mathrm{AgCl}$. The electrode prepared by $\mathrm{MnO}_{2}$ deposition at $1.0 \mathrm{~V}$ shows a behavior close to what is usually observed for a $\mathrm{MnO}_{2}$-based bulk electrode, i.e. capacitance increases during the first tens of cycles before to stabilize to a threshold value (Fig. 4b) [19]. This behavior points out that $\mathrm{MnO}_{2}$ layer is, in this case, quite thick. The same behavior has already been observed for thick $\mathrm{MnO}_{2}$ films precipitated at the surface of porous carbons [10].

In contrast, the capacitance of $\mathrm{Ni}$ nanoplot supported $\mathrm{MnO}_{2}$ prepared at $0.85 \mathrm{~V}$ quickly fades down upon cycling as demonstrated by the $30 \%$ loss of the initial capacitance after 500 cycles (Fig. $4 \mathrm{~b}$ ). This trend is characteristic of a thin layer of active material. This later point is also supported by the initial capacitance at $135 \mathrm{~F} / \mathrm{g}$, higher than the initial capacitance measured for the electrode prepared by deposition at $1.0 \mathrm{~V}$. Noteworthy is the relatively low value for this initial capacitance while $\mathrm{MnO}_{2}$ thin films have shown capacitances up to $900 \mathrm{~F} / \mathrm{g}$ [20]. Obviously, decreasing the working potential from $1.0 \mathrm{~V}$ to $0.85 \mathrm{~V}$ has enhanced the homogeneity of the deposit and improved the electrochemical performances of the $\mathrm{MnO}_{2} / \mathrm{Ni}$ nanorods electrode. However in both cases, the deposition remains controlled by diffusion of the $\mathrm{Mn}^{2+}$ species through the nanostructure towards the nanoplot surface where the oxidation to $\mathrm{Mn}^{4+}$ and subsequent $\mathrm{MnO}_{2}$ deposition proceed. A pulse method has been developed to allow an optimal supplying of $\mathrm{Mn}^{2+}$ species in the constrained volume built by the nanoplot network, making them available for oxidation at the platting solution/nickel nanoplot interface.

\subsection{Two-step potentiostatic method}

The working potential at $0.85 \mathrm{~V}$ was applied for $10 \mathrm{~s}$ and followed by a resting step at open circuit voltage (OCV) for $2 \mathrm{~s}$. This scheme has been repeated over 360 and 720 cycles. By using this method, Ni nanorods appeared as coated individually by $\mathrm{MnO}_{2}$ (Fig. 5). To evaluate the weight of deposited $\mathrm{MnO}_{2}\left(m_{\mathrm{MnO}_{2}}\right)$, the total charge has been calculated by integration of the current of each $0.85 \mathrm{~V}$ step through $10 \mathrm{~s}$ electrolysis duration. From this more homogeneous $\mathrm{MnO}_{2}$ layer, higher performances were expected and hence initial capacitance was measured at $C_{1}=190 \mathrm{~F} / \mathrm{g}$. The capacity retention, far from perfect, was improved too since the capacity loss was limited to $20 \%$ after 500 cycles (Fig. 6b).

For electrodes prepared by both deposition approaches capacity fadings are characteristic of a progressive dissolution of the electroactive material thanks to obviously too high upper potential limit used for these long term cycling tests. The potential window used was first adjusted to extract the highest initial capacity and has obviously not been optimised for long term cycling. It also corresponds to the potential window used in previous studies on capacitive behavior of $\mathrm{MnO}_{2}$ electrodeposited on stainless-steel substrates [15].

As demonstrated in Fig. 6a, the most remarkable result lies in the maintain of high capacitance values of the 3600 s-electrode under high charge/discharge rate. For comparison purpose, $\mathrm{MnO}_{2}$ was electrodeposited on a flat Ni substrate using the same electrolysis parameters as previously described for the 3600 s-electrode. Electrode surface composed of disordered $\mathrm{MnO}_{2}$ nanosheets is close to what has been observed for $\mathrm{MnO}_{2}$ deposits onto flat stainlesssteel surfaces [15]. Fig. 6a depicts the capacitance of such a deposit as a function of the applied scan rate: the higher the scan rate, the lower the capacitance. The same behavior has been observed using thin films deposited onto flat Ni current collectors. It is characteristic of $\mathrm{MnO}_{2}$ bulk electrode for which capacitances are fading for higher scan rate because of the diffusion limitation of electrolytic species in the material structure [21]. In contrast, the maintain of the capacitance in the whole scan rate range explored in this study, can be explained by the facile diffusion of electrolyte ions through the open structure provided by $\mathrm{Ni}$ nanorods. 


\subsection{Electrochemical impedance spectroscopy (EIS)}

EIS analyses confirm the idea of a diffusion of electrolyte through the $\mathrm{MnO}_{2}$-coated $\mathrm{Ni}$ nanorods facilitated by the electrode open structure and leading to high capacitances at high scan rates. The EIS plot in Fig. 7a is typically the one observed for a compact $\mathrm{MnO}_{2}$ film since there is no diffusion limitation. However, the absence of any diffusion like behavior at $45^{\circ}$ generally observed for highly porous electrodes $[16,17]$ and usually described using a Transmission Line Model of a combination of series-parallel RC circuits [16] evidences the absence of porosity inside the $\mathrm{MnO}_{2}$ film structure. The change in the plot slope above 50 cycles in the low frequency region where the capacitive behavior can be seen indicates an increase of the charge transfer resistance during cycling that can be assigned to the slow dissolution of $\mathrm{MnO}_{2}$.

The main differences with the plot presented in Fig. 7b is the presence of a Warburg-like sloppy behavior in the middle frequency range [16]. This stands for the ion migration inside the porosity of the electrode: the lower the frequency, the deeper the penetration of ions from the electrolyte into the depth of the electrode [17]. The $\mathrm{MnO} 2$ coating obtained under pulsed galvanostatic conditions was found to be thin and conformal onto the $\mathrm{Ni}$ rods, leading to an open porous structure for the whole film as compared to what was obtained in Fig. 7a. The EIS plots confirm this difference. Another difference between the two films is that the low frequency range of the Nyquist plot in Fig. 7b is not so affected by the cycle number as compared to Fig. 7a. The $\mathrm{MnO}_{2}$ dissolution, responsible for the change observed in Fig. 7a for potentiostatic deposited films, is slowing down for $\mathrm{MnO}_{2}$ films with an open porous structure thanks to the Ni nanorods. In Fig. 7b, an increase in the impedance at high frequency is measured after 500 cycles. Since it is the dominant effect in this frequency range, it is usually associated to an increase in the electrolyte resistance upon cycling. This is usually true, as long as electrode remain unchanged, both chemically or geometrically. In the present case, it certainly comes from a resistance increase upon cycling because of the progressive passivation of the electrode at the solid-liquid interface. The generation of a complex nickel/manganese oxide such as $\mathrm{NiMnO}_{2}$ at the interface could originate for the observed impedance increase.

\section{Conclusions}

Ni nanorods prepared by electrochemical growth through a porous AAO membrane have been successfully used as substrate for the controlled electrochemical deposition of $\mathrm{MnO}_{2}$. Continuous and pulse potentiostatic methods have been used resulting in the deposition of $\mathrm{MnO}_{2}$ of distinct morphologies. The latter method led to more homogeneous deposits at the nanoplot surfaces for a maintain of the original open structure. The best electrochemical performances exhibited capacitances up to $190 \mathrm{~F} / \mathrm{g}$ with a loss of about $20 \%$ after 500 cycles. The evaluation of the scan rate impact on capacitance pointed out an outstanding behavior: in contrast with what is usually observed for bulk $\mathrm{MnO}_{2}$-based electrodes, in the present cases, capacitances remain high at high charge/discharge rates. This behavior was confirmed by EIS analyzes showing that $\mathrm{MnO}_{2}$-coatings seem thin enough and uniformly distributed to give the prepared $\mathrm{MnO}_{2} / \mathrm{Ni}$ electrode a porous structure facilitating the diffusion of electrolytic species through the whole electrode volume. Such remarkable behavior highlights potential applications for these prepared $\mathrm{MnO}_{2} / \mathrm{Ni}$ nanorods electrodes in high-power micro-devices.

\section{References}

[1] H.Y. Lee, J.B. Goodenough, J. Solid State Chem. 144 (1999) 220

[2] H.Y. Lee, V. Manivannan, J.B. Goodenough, Comp. Rendus l'Acad. Sci., Ser. IIC: Chem. 2 (1999) 565.

[3] M. Toupin, T. Brousse, D. Belanger, Chem. Mater. 16 (2004) 3184.

[4] J.-K. Chang, S.-H. Hsu, W.-T. Tsai, I.-W. Sun, J. Power Sources 177 (2008) 676.

[5] M.-W. Xu, D.-D. Zhao, S.-J. Bao, H.-L. Li, J. Solid State Electrochem. 11 (6) (2007) 1101.

[6] C.C. Hu, T.W. Tsou, Electrochem. Commun. 4 (2002) 105.

[7] X.P. Dong, W.H. Shen, J.L. Gu, L.M. Xiong, Y.F. Zhu, Z. Li, J.L. Shi, J. Phys. Chem. B 110 (2006) 6015.

[8] E. Raymundo-Pinero, V. Khomenko, E. Frackowiak, F. Beguin, J. Electrochem. Soc. 152 (2005) A229.

[9] S.J. Pan, Y.J. Shih, J.R. Chen, J.K. Chang, W.T. Tsai, J. Power Sources 187 (2009) 261.

[10] Y. Lei, C. Fournier, J.L. Pascal, F. Favier, Micropor. Mesopor. Mater. 110 (2008) 167.

[11] L. Taberna, S. Mitra, P. Poizot, P. Simon, J.M. Tarascon, Nat. Mater. 5 (2006) 567.

[12] L. Bazin, S. Mitra, P.L. Taberna, P. Poizot, M. Gressier, M.J. Menu, A. Barnabe, P. Simon, J.M. Tarascon, J. Power Sources 188 (2009) 578.

[13] J. Hassoun, S. Panero, P. Simon, P.L. Taberna, B. Scrosati, Adv. Mater. 19 (12) (2007) 1632.

[14] C. Villevieille, F. Robert, P.L. Taberna, L. Bazin, P. Simon, L. Monconduit, J. Mater. Chem. 18 (48) (2008) 5956

[15] Y.K. Zhou, M. Toupin, D. Bélanger, T. Brousse, F. Favier, J. Phys. Chem. Solids 67 (2006) 1351.

[16] R. de Levie, Electrochim. Acta 9 (1964) 1231

[17] P.L. Taberna, P. Simon, J.F. Fauvarque, J. Electrochem. Soc. 150 (2003) A292.

[18] R.J. Smith, R.E. Hummel, J.R. Ambrose, Corros. Sci. 27 (8) (1987) 815

[19] T. Brousse, P.L. Taberna, O. Crosnier, R. Dugas, P. Guillemet, Y. Scudeller, Y. Zhou, F. Favier, D. Bélanger, P. Simon, J. Power Sources 173 (2007) 633.

[20] S.C. Pang, M.A. Anderson, T.W. Chapman, J. Electrochem. Soc. 147 (2000) 444.

[21] M. Toupin, T. Brousse, D. Belanger, Chem. Mater. 14 (9) (2002) 3946. 